\title{
Interdisciplinary Trauma Management in an Elderly Patient, A Case Re- port
}

\author{
George T. Felt and Ahmad Soolari*
}

George Felt, DDS, MAGD, ABGD has a Certificate in Periodontics from NYU, and a Certificate from Progressive Orthodontics Seminars. He is Board Certified by the American Board of General Dentistry. He practices general dentistry in Meredith, $\mathrm{NH}$

Certificate in Periodontics from the Department of Eastman Dental and a MS degree from the University of Rochester, Rochester, New York. Dr. Soolari operates a specialty practice in the Silver Spring, Gaithersburg and Potomac area of Montgomery County, Maryland

\begin{abstract}
The current report reviews a case of mixed dental trauma consequent to a fall by an older patient. The patient's teeth were forced out of alignment by the trauma and suffered pulpal necrosis. Treatment involved not only healing the acute injuries, but also attending to some subtle delayed problems that became apparent during treatment. Treatments involving endodontics, periodontics, orthodontics, and restorative dentistry were used to address all of the patient's concerns. This insured that the traumatic occlusion was corrected, appropriate esthetics was restored and normal speech and function was regained. All signs of trauma were recognized, every treatment step was documented, and appropriate follow-up was provided throughout the recovery period.
\end{abstract}

Keywords: Dental trauma, interdisciplinary cooperation, trauma management.

\section{INTRODUCTION}

The many reports in the literature of treatment following dental trauma attest to the potential for these injuries to be complex and multifaceted. In older patients, there may be surprising consequences due to a lifetime of muscle memory. The patient presented here suffered mixed dental trauma as the result of a fall, with an unusual side effect of painful lip biting prompted by her pre-fall occlusion. This patient's teeth were forced out of alignment by the trauma and suffered pulpal necrosis at that time. In cases such as this, a team approach involving the endodontist, periodontist, orthodontist, and restorative dentist can ensure that any traumatic occlusion is corrected, appropriate esthetics are restored, normal speech and function are regained, all signs of trauma are recognized, every treatment step is documented, and appropriate follow-up is provided throughout the recovery period.

\section{INITIAL PRESENTATION}

On April 19, 2012, the patient, then age 73, presented for treatment of injuries suffered 5 days previously (4/14/2012). She had fallen in front of a store and hit her face and mouth hard on the pavement. She stated that this had caused her a great deal of pain and bruised her face. She added that her teeth had not felt the same since the fall because the fall

*Address correspondence to this author at 11616 Toulone Dr., Potomac, MD 20854; Tel: 301 674-9815; Fax: 240845 1087;

E-mail: asoolari@gmail.com caused a change in her bite in the front, and she had not been eating normally since then.

Pictures were taken to document her condition (Figs. 1-4, 6, 7). Alginate impressions of her upper and lower teeth were made to enable fabrication of diagnostic models. Radiographs were taken. The periapical radiographs (Fig. 5) showed a shadow around the roots of her front teeth, which indicated luxation injuries to the central incisors. She was able to make full bilateral contact with her posterior teeth, but her upper and lower incisors also made contact in centric occlusion, an unwelcome result of the fall. Previously, the patient never had anterior tooth-to-tooth contact - her preinjury occlusion was a Class II malocclusion with a large overjet (approximately $5 \mathrm{~mm}$ ) - so this altered bite condition bothered her. Bruises to her face and lips were also noted.

The patient was informed that she may need root canal therapy on one or more of her front teeth to resolve problems with the injured dental pulps. She was in no acute pain from the dental problems that she was experiencing at the time of initial presentation, but she was distressed by the changes in tooth positions, damage to her appearance, and functional discomfort brought on by the incident. We concluded the visit with plans to follow up in the near future.

FOLLOW-UP EVALUATIONS, DIAGNOSIS, AND TREATMENT RECOMMENDATIONS

On June 5 and June 20, 2012, the patient returned for follow-up evaluations. Clinical examination revealed the following: 

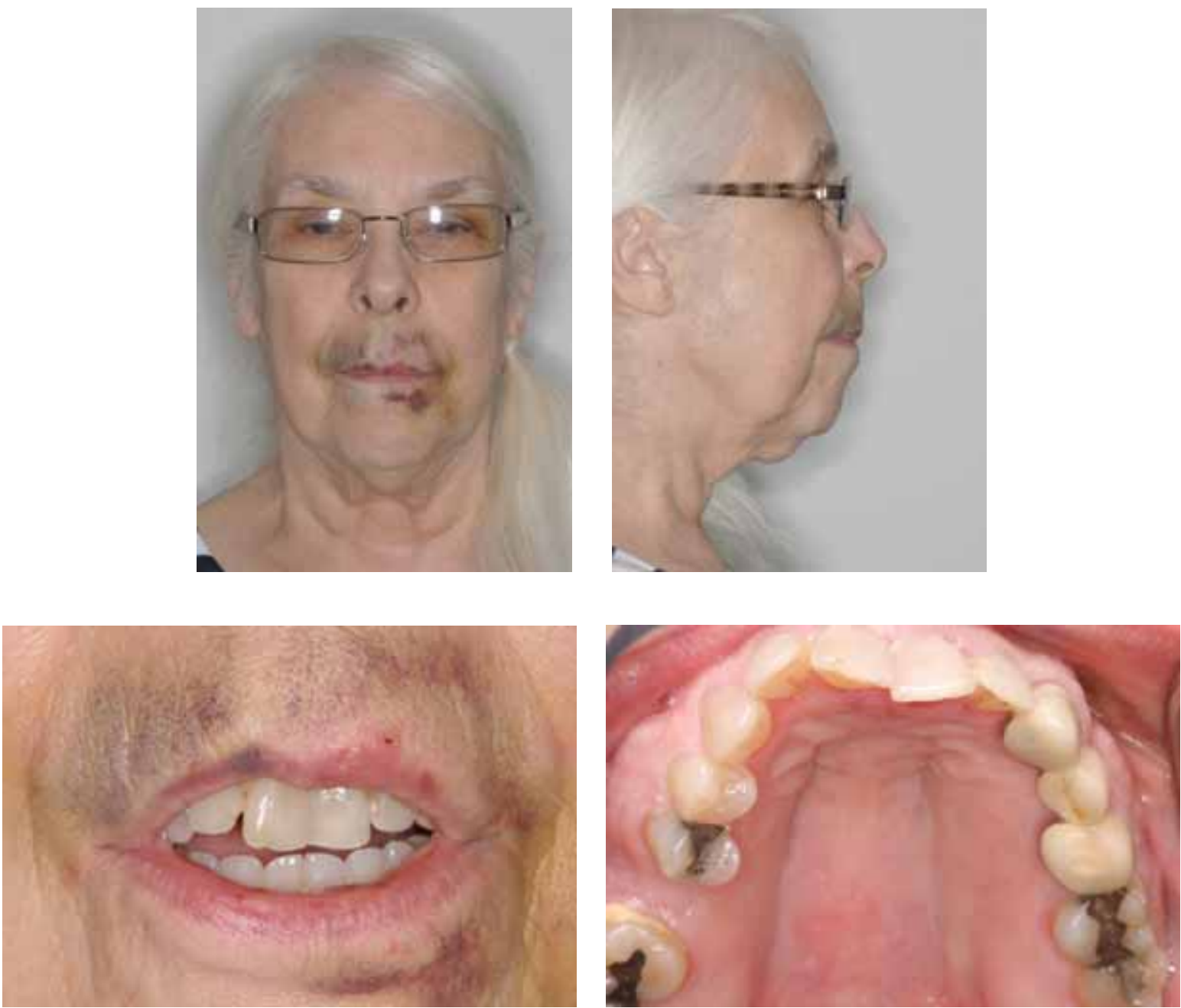

Figs. (1 to 4). Initial presentation.

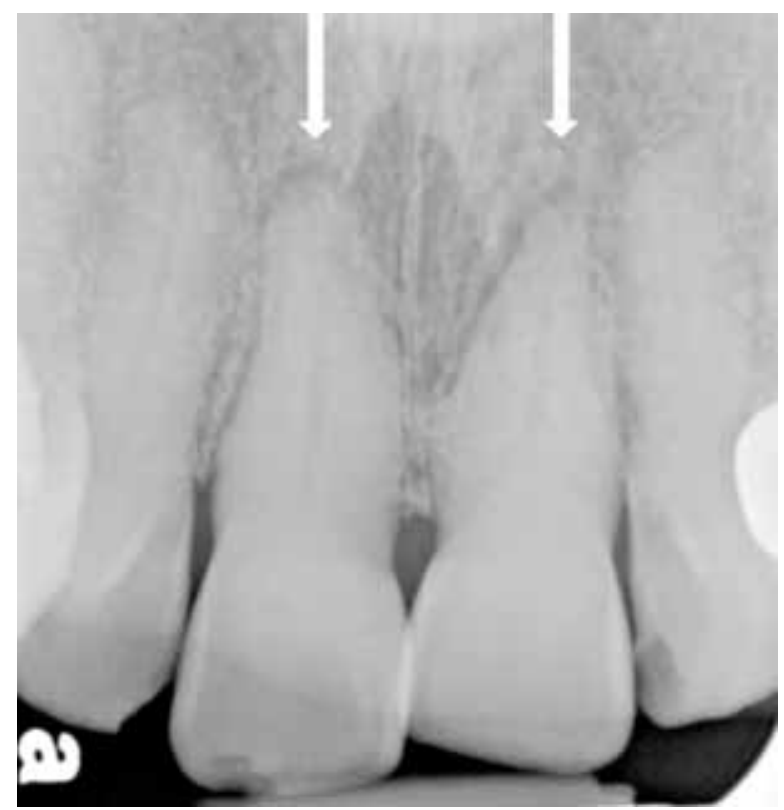

Fig. (5). Initial periapical radiograph. Luxation of the incisors is apparent. 

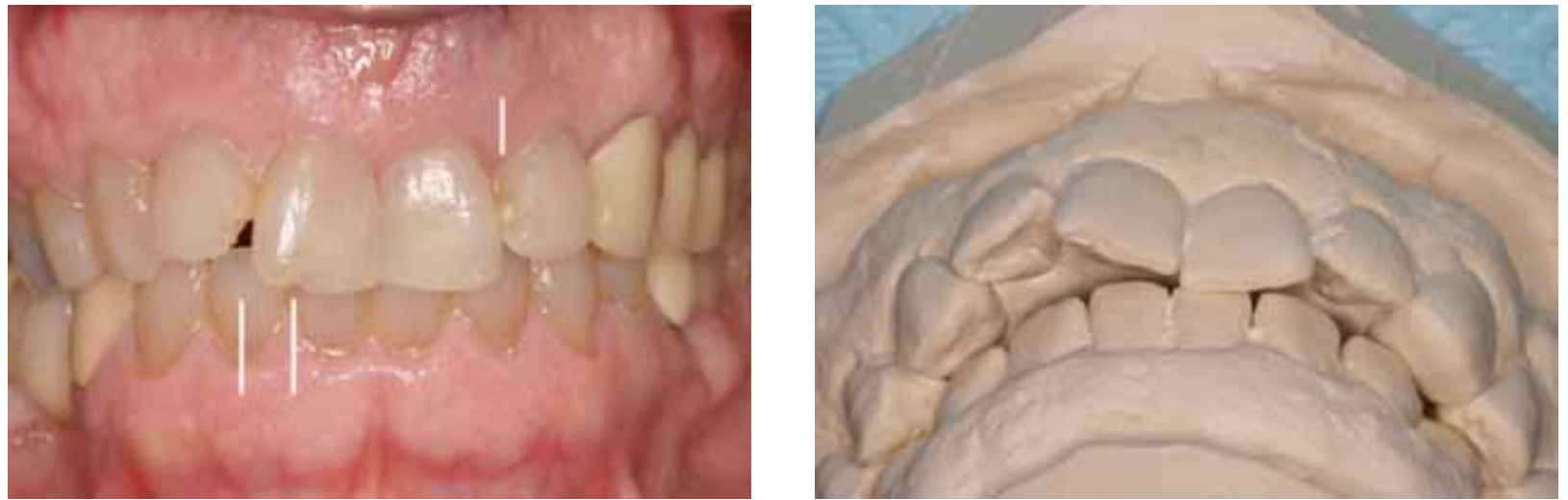

Figs. (6 to 7). Initial intraoral views and cast, June 2012. Lines indicate chips $(11,22)$ and fracture (12).

1) Chipped and cracked teeth (FDI \#12, 11, and 22).

2) Pulp necrosis at \#12, 11, 21, and 22.

3) Altered tooth positions ("luxation") at \#11 and 21, most notably at \#21 (left central).

4) Altered bite, that is, the anterior teeth "did not meet the way they used to." This was causing her to bite her lip very frequently in spite of her wish to not do so; she could not avoid this because her teeth were now in the "wrong place" relative to her habitual muscle movement patterns. Examination of articulated study casts enabled diagnosis of lost overjet, and clinical observation revealed functional prematurity in protrusive movements (Fig. 7).

Recommended treatment included the following:

1) Composite restorations to repair fractured teeth \#12, 11 , and 22 . These would have to be replaced periodically because the material has an average service life of about 7 years.

2) Root canal therapy as needed at \#12,11, 21, and 22 to remove the necrotic pulps, and restorations to close the access preparations after root canal therapy.

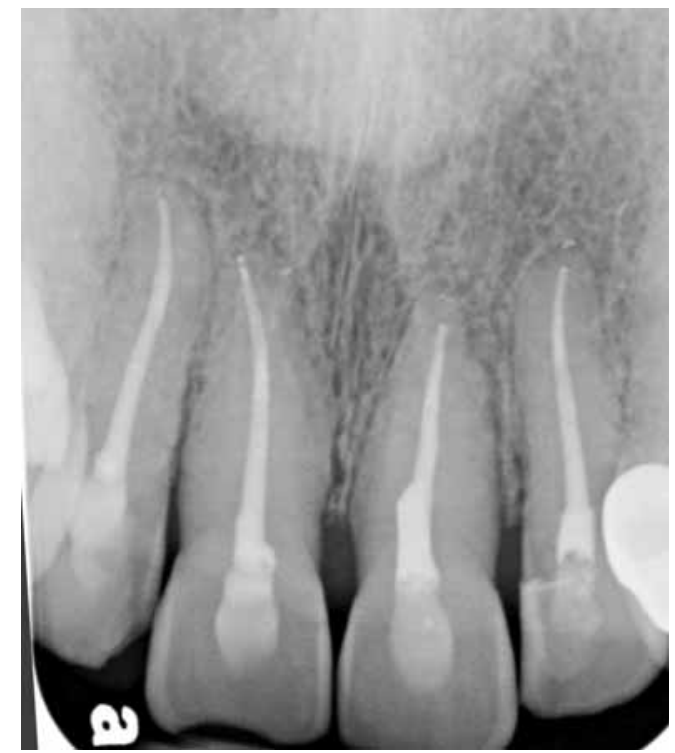

Fig. (8). Periapical radiograph showing the teeth after root canals on all four incisors.
3) Orthodontic therapy to move her anterior teeth back to their pre-trauma positions.

4) Occlusal adjustment (bite correction) so that the patient would be able to bite and chew easily. This would be accomplished by orthodontic therapy and, if needed, additional fine tuning (equilibration).

These treatments were recommended solely and specifically to remedy the damage that was done at the time of the incident. The patient's teeth were generally in good repair apart from the issues described here, so no other treatment (except cleanings for maintenance, which are excluded from this discussion) was indicated for this patient at this time.

\section{TREATMENT}

By the time of the second follow-up visit, the patient complained of persistent pain in the area of her front teeth. While recovering pulps may be unresponsive after trauma, the presence of persistent tooth pain that develops several days after trauma is a clear indication for root canal therapy.

Root canal therapy was performed on teeth \#12, 11, 21, and 22 to relieve the pain and enable retention of the teeth (Figs. 8 and 9). The root canals were done two at a time, in a total of two visits (7/18/2012 and 8/16/2012). Composite restorations were then placed $(10 / 18 / 2012)$ to close the access preparations and repair the fractured areas of her front teeth (Figs. 8 and $\mathbf{9}$ ).

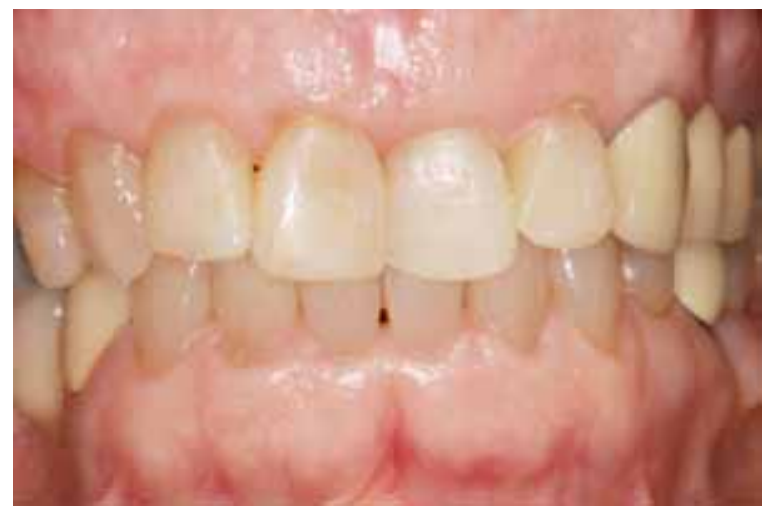

Fig. (9). View after composite restorations but before orthodontic repositioning. The teeth were still rotated in toward the tongue at the midline as a result of the fall. 

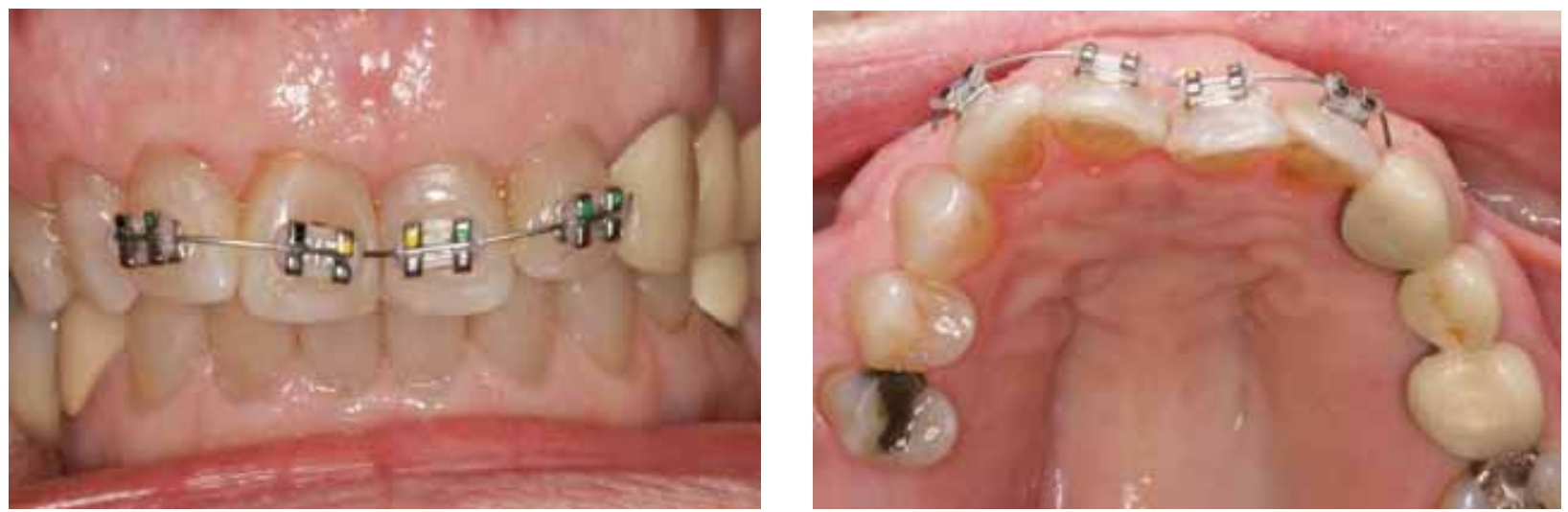

Figs. (10 and 11). Orthodontic therapy involved .014-inch NiTi wire (shown) and .018 x .025-inch NiTi (not shown).

On November 27, 2012, the patient complained again of lip-biting caused by the traumatic repositioning of her teeth ("It wakes me up at night and I bite my lip there"). We explained that although the repositioning of her teeth at the time of the fall happened quickly, the correction of that condition would require orthodontic therapy, which is a slow process. She requested this treatment as soon as possible, as she was suffering nearly continuously from the lip-biting pain. She was quite helpless to correct this problem on her own, because the habitual patterns of eating, speaking, and swallowing were deeply ingrained at her relatively advanced age. This was a source of much frustration to her, but it is not uncommon for patients in her age group to experience difficulty in adapting to significant changes in the positions of their teeth.

On January 24, 2013, orthodontic brackets were placed on her teeth, and we started a program of limited orthodontic treatment that was designed to restore her teeth to their original positions. In other words, the orthodontic treatment was not done for esthetic reasons; it was done primarily to restore her ability to enjoy normal oral function without pain. It was reasoned that if the teeth were restored to their former positions (Class II, Division 1, large overjet), then the lip biting caused by their altered positions would cease. Secondarily, it was considered reasonable to restore her teeth to an esthetic appearance that approximated the way she looked before the incident. In other words, this was not a "Hollywood smile makeover"; it was a good-faith effort to restore her teeth to the condition they were in before the incident-

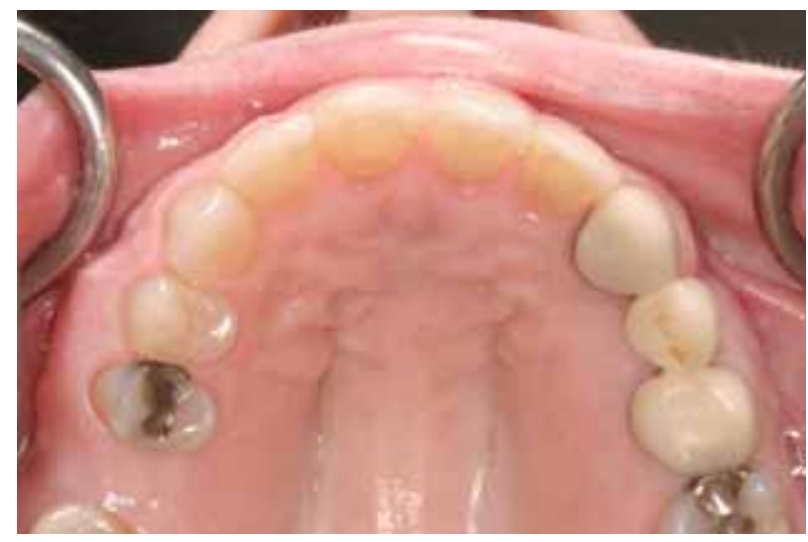

Fig. (12). Upper arch after orthodontia. nothing more, nothing less. This was discussed with the patient, who then approved the concept and consented to the specific treatments that were rendered to implement this concept (Figs. 10 and 11).

The goal of orthodontic treatment was to return her teeth to their original pre-trauma positions. No effort was made to correct her Class II malocclusion, which was recognized and discussed but deemed unimportant by the patient. She had always been Class II, she was used to it, and it had not been a problem for her. Therefore, she did not wish to undertake any correction of that condition, and we were able to accommodate her preference in good faith. NiTi round wire (.012-inch) followed by NiTi heat-activated wire $(.018 \times$ .025 -inch) in fixed metal (.022-inch) brackets was used to reposition the incisors (Figs. 11 and 12). The arch form was restored to a close approximation of the form that it had enjoyed prior to the incident. This correction enabled the patient to resume normal function by eliminating the protrusive interference and the lip biting problem. Examination of post treatment study casts shows overjet restored to original condition (Fig. 13). The comfort and restoration of normal function finally enabled the patient to smile again (Fig. 14).

\section{DISCUSSION}

The management of this case required a multidisciplinary approach to the treatment of traumatic injuries. Many cases of trauma treated with a team approach have been reported in

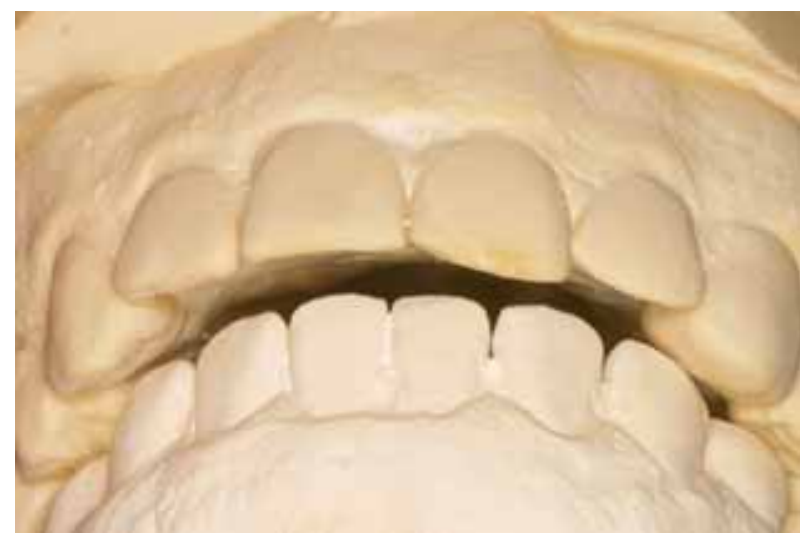

Fig. (13). Protrusive interference corrected (CO). 


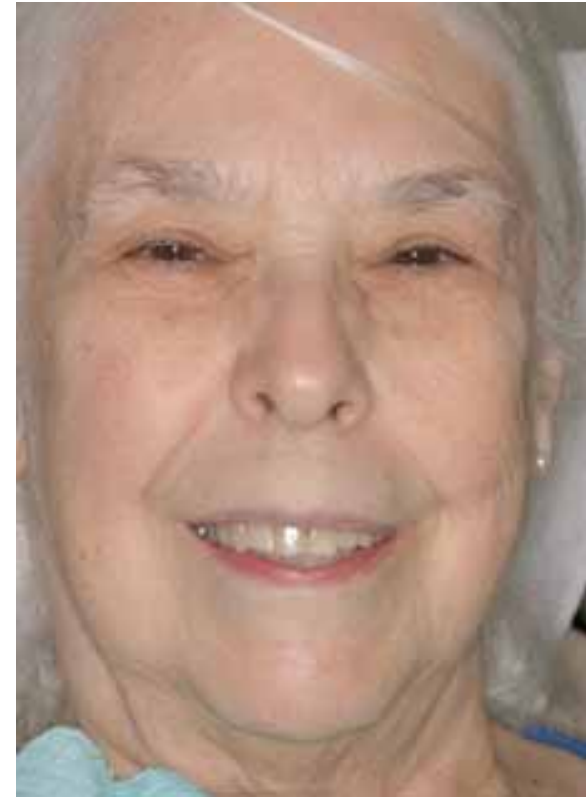

Fig. (14). Completed case - smiling again!.

the literature [1-3], and a few authors have even compiled all reports in efforts to identify common principles of treatment for different types of dental trauma [4-6]. It seems clear that interdisciplinary management is frequently-if not alwaysrequired in cases of dental trauma [2, 5, 7-12]. Sharma et al, [5] Cohen-Carneiro et al. [1], Steiner and West [13], and Mathu-Muju, et al. [10] all reported on cases that, because of their complexity, necessitated cooperation between dental specialties. Levin et al. [9] stated that "an individual treatment plan for each patient is necessary. General rules do not apply." Kindelan et al. [7] and Day et al. [8] presented a two-part series on the interdisciplinary management of traumatized teeth. In agreement with many other clinicians, they concluded that interdisciplinary cooperation was essential, as was the involvement of an orthodontist in the team, especially for teeth with a poor prognosis.

Ruiz [12] especially stressed that clear communication with the patient as well as management of expectations were crucial in ensuring patient satisfaction: "It is important to acknowledge that the patient's satisfaction is not always consistent with the final results; the result may be clinically successful, but the patient may still be unhappy." [12, p. 546] He urged a systematic approach to diagnostic documentation to ensure that all functional and esthetic aspects of treatment were properly taken into consideration during treatment planning.

Interdisciplinary decision-making may concern whether and how to treat traumatically devitalized teeth [14] and whether endodontically treated teeth can be effectively moved through orthodontic forces $[3,7,13,15,16]$. The timing of such treatments is often a concern, although Medeiros and Mucha [4] observed no difference in the success of orthodontic extrusion of traumatically intruded teeth, regardless of whether treatment began soon after the trauma ( $<10$ weeks) or more than 3 months after the injury. Sübay et al. [16] reported on the delayed management of a luxated incisor. They successfully treated the necrotic tooth, begin- ning 1 month after the trauma, with endodontics and orthodontic repositioning, avoiding surgery, extraction, and implant treatment. That is exactly what was done here with the 11 and 21.

The treatment considerations specific to traumatized teeth are many. Levin et al. [9] noted that dentists must carefully assess the status of the alveolar bone; especially in the esthetic zone, the alveolar dimensions must be preserved. Oikarinen [17] stressed that trauma to the jaw often involved additional tooth trauma that may not be apparent in the immediate aftermath of the injury. In the current patient, the luxation of the front teeth was obvious but the problem with lip-biting and related pain only became apparent over time. Lin et al. [18] (along with the American Association of Endodontists, the International Association of Dental Traumatology, and the Royal College of Surgeons of England) presented a modified research-based protocol for treatment of luxation and avulsion.

\section{CLINICAL SUMMARY AND CONCLUSION}

This patient suffered significant dental injuries when she tripped over something on a sidewalk and fell forward onto the hard surface, hitting the front of her face and causing damage to her mouth and teeth. The patient presented to our attention 5 days after the incident with bruised skin about the mouth, several chipped or broken teeth, dental pulps in the four upper front teeth that were damaged beyond repair, and teeth that were luxated (laterally) in a way that interfered with the normal use of her mouth. Pain from the dying pulps and from the involuntary lip biting that was caused by luxation of her upper front teeth was of extended duration and caused substantial distress, interfering with the enjoyment of her daily activities for a period of several months.

With the patient's consent, a series of treatments was performed with the goal of correcting the problems that resulted from the fall. These treatments included root canal therapy, composite restorations to restore the chipped and broken tooth structures, and fixed orthodontic appliances. The treatment enabled the patient to return to a condition of normal oral health and function after a little more than 13 months of treatment.

It is important for legal reasons to mention that some of the restorative treatment that was done is not expected to last forever, and that significant restorative treatments will likely be needed when the recently placed composite fillings eventually fail. It is not known at this time whether future restorations will involve crowns or merely replacement fillings, but clearly the time will come when additional restorations will be needed that would never have been needed in the absence of the trauma that brought this patient into the practice. A full account of damages must include consideration of future treatment needs that are directly and exclusively related to the injury, although it is difficult to estimate the value of those needs due to the fact that fees may change with time. Detailed documentation of all present and future problems and treatments related to an accident is a significant responsibility for providers, as the quality of the record may impact on the patient's ability to recover damages via insurance coverage and/or litigation. 
A multidisciplinary approach to dental trauma should be taken when teeth are out of alignment and have lost vitality; a pooling of endodontic, periodontic, orthodontic, and prosthodontic (restorative) perspectives resulted in successful treatment of this patient. It is vital in similar cases to eliminate any traumatic occlusion, return the patient to a "normal" look (for the patient), and to ensure that he or she regains normal speech and function (chewing). Dentists must examine patients carefully to ensure that all signs of trauma are recognized and documented, and careful follow-up is essential.

\section{CONFLICT OF INTEREST}

The authors confirm that this article content has no conflict of interest.

\section{ACKNOWLEDGEMENTS}

Editorial assistance from Jennifer P. Ballinger, ELS, is gratefully acknowledged.

\section{DISCLOSURE}

Neither author has a financial interest in any of the products or companies mentioned in this article.

\section{REFERENCES}

Cohen-Carneiro F, Sponchiado EC Jr, Garcia LF, Yurtsever FV, Pontes DG, Sena A. Coronal reconstruction following anterior teeth traumatism: multidisciplinary treatment. Gen Dent 2013; 61(5):47-9.

[2] Kalwitzki M, Weiger R. An intrusion injury as an example of interdisciplinary aspects in dental traumatology: a case report. Quintessence Int 2005; 36(3): 234-42.

[3] Moura Lde F, de Lima Mde D, Leao VL, de Moura MS, de Moura WL. Interdisciplinary approach to traumatized permanent anterior teeth: case report and 10-year follow-up. Gen Dent 2010; 58(1): 68-71.

[4] Medeiros RB, Mucha JN. Immediate vs late orthodontic extrusion of traumatically intruded teeth. Dent Traumatol 2009; 25(4): 380-5. doi: 10.1111/j.1600-9657.2009.00771.x.
Sharma D, Garg S, Sheoran N, Swami S, Singh G. Multidisciplinary approach to the rehabilitation of a tooth with two trauma episodes: systematic review and report of a case. Dent Traumatol 2011; 27(4): 321-6.

[6] Chaushu S, Shapira J, Heling I, Becker A. Emergency orthodontic treatment after the traumatic intrusive luxation of maxillary incisors. Am J Orthod Dentofacial Orthop 2004; 126(2):162-72.

[7] Kindelan SA, Day PF, Kindelan JD, Spencer JR, Duggal MS. Dental trauma: an overview of its influence on the management of orthodontic treatment. Part 1. J Orthod 2008; 35(2): 68-78. doi: $10.1179 / 146531207225022482$

[8] Day PF, Kindelan SA, Spencer JR, Kindelan JD, Duggal MS. Dental trauma: part 2. Managing poor prognosis anterior teethtreatment options for the subsequent space in a growing patient. J Orthod 2008; 35(3):143-55. doi: 10.1179/146531207225022590

[9] Levin I, Ashkenazi M, Schwartz-Arad D. Preservation of alveolar bone of un-restorable traumatized maxillary incisors for future. Refuat Hapeh Vehashinayim 2004; 21(1): 54-9, 101-2.

[10] Mathu-Muju K, McIntyre JD, Lee JY, Tyndall DA, Roberts MW. Multidisciplinary trauma management: a case report. Dent Traumatol 2009; 25(1): e5-11.

[11] Palazzo M, Massai L. The importance of the operating sequence: a multidisciplinary treatment approach. Pract Proced Aesthet Dent 2007; 19(8): 483-9.

[12] Ruiz JL. Achieving optimal esthetics in a patient with severe trauma: using a multidisciplinary approach and an all-ceramic fixed partial denture. J Esthet Restorative Dent 2005; 17(5): 285-91.

[13] Steiner DR, West JD. Orthodontic-endodontic treatment planning of traumatized teeth. Semin Orthod 1997; 3(1): 39-44.

[14] Derhalli M, Mounce RE. Clinical decision making regarding endodontics versus implants. Compend Contin Educ Dent 2011; 32(4): 24-6, 28-30, 32-5; quiz 36.

[15] Hamilton RS, Gutmann JL. Endodontic-orthodontic relationships: a review of integrated treatment planning challenges. Int Endod $\mathbf{J}$ 1999; 32(5): 343-60.

[16] Sübay RK, Kayataș M, Caniklioğlu C. Delayed multidisciplinary management of an extrusively luxated maxillary central incisor. Dent Traumatol 2007; 23(2): 82-4.

[17] Oikarinen KS. Clinical management of injuries to the maxilla, mandible, and alveolus. Dent Clin North Am 1995; 39(1): 113-31.

[18] Lin S, Zuckerman O, Fuss Z, Ashkenazi M. American Association of Endodontists; International Association of Dental Traumatology; Royal College of Surgeons of England. New emphasis in the treatment of dental trauma: avulsion and luxation. Dent Traumatol 2007; 23(5): 297-303.

Received: April 27, 2014

Revised: September 09, 2014

Accepted: September 28, 2014

(C) Felt and Soolari; Licensee Bentham Open.

This is an open access article licensed under the terms of the Creative Commons Attribution Non-Commercial License (http://creativecommons.org/licenses/by-nc/3.0/) which permits unrestricted, non-commercial use, distribution and reproduction in any medium, provided the work is properly cited. 